\title{
T CELL LYMPHOMA IN THE ATRIUM OF A YOUNG BULL
}

\author{
G. FARJANIKISH ${ }^{1}$, O. DEZFOULIAN ${ }^{1} \&$ K. QEISARBEIGI ${ }^{2}$
}

${ }^{1}$ Department of Pathobiology, Faculty of Veterinary Medicine, Lorestan University, Khorramabad, Iran; ${ }^{2}$ Veterinary Supervision of Khorramabad Region, Khorramabad, Iran

\section{Summary}

Farjanikish, G., O. Dezfoulian \& K. Qeisarbeigi, 2018. T cell lymphoma in the atrium of a young bull. Bulg. J. Vet. Med., 21, No 4, 483-488.

\begin{abstract}
In this report, T-cell lymphoma in the atrium of a 1.5-year-old Holstein bull is described. Macroscopically, a large white to a yellow tumour mass with a size of $4.5 \times 3.5 \times 2 \mathrm{~cm}$ was observed in the left atrium. Histopathological examination revealed extensive infiltration of medium- to large-sized lymphocytic cells with round to oval nuclei and stippled chromatin, surrounded by a narrow rim of pale eosinophilic cytoplasm. Immunohistochemically, the tumour cells indicated positivity with CD3 and Ki-67, but negativity with CD79 $\alpha$, CD20 and S100. On the basis of the histologic and immunohistochemical findings, this tumour was diagnosed as a T-cell lymphoma.
\end{abstract}

Key words: atrium, cow, immunohistochemistry, lymphoma

Bovine lymphoma is one of the several common neoplasms identified in cattle causing considerable contention in terms of nomenclature and classification. Concerning pathogenesis and clinical pathology, this neoplasm in cattle is classified into enzootic bovine leukosis (EBL) and sporadic bovine leukosis (SBL) (Tani et al., 1997). EBL is most often associated with the enzootic leukemia virus and cattle affected with this form of lymphoma are usually 4-8 years of age. Among cattle, the tumour is commonly detected in the uterus, abomasum, heart, and peripheral lymph nodes. The SBL is not associated with the bovine leukaemia virus and can be classified into three further types with respect to the preferential sites of the neoplasia and age of the affected animal: calf type, thymic type, and skin type (Sasaki et al., 1997; Step et al., 2001; Harbo et al., 2004).

Although lymphomas are relatively uncommon in calves, the neoplasms are of interest due to their occurrence early in life (Meuten \& Harvey, 2008; Step et al., 2001). Primary cardiac lymphomas are extremely rare and the most common gross appearance of tumours is as nodular or polypoid masses which predominantly involve the pericardium having variable 
myocardial infiltration (Constantino et al., 1987; Holladay et al., 1992).

The present report describes the clinical, histopathological and immunohistochemical features of an atrial lymphoma in a young bull.

Case presentation. A Holstein bull 1.5 years of age, was presented to the clinic with a one-month history of progressive loss of appetite, decreased activity and loss of condition. The heart rate dropped down to $48 \mathrm{bpm}$, the respiratory rate was 28 breaths per minute, and the rectal temperature was $38^{\circ} \mathrm{C}$. A moderate degree of dyspnea was observed; however, the animal was alert and did not cough. During the physical examination, no heart sounds could be auscultated and no jugular distention or pulsation was observed. The prefemoral and prescapular lymph nodes were not enlarged.

The bull had leukocytosis with neutrophilia $(14,100$ leukocytes/ $\mu \mathrm{L}$; normal $5,000$ to 10,000 leukocytes/ $\mu \mathrm{L})$. The concentrations of blood urea $(13.0 \mathrm{mmol} / \mathrm{L}$; normal 2.4 to $6.5 \mathrm{mmol} / \mathrm{L}$ ) and creatinine (119 $\mu \mathrm{mol} / \mathrm{L}$; normal 55 to $103 \mu \mathrm{mol} / \mathrm{L}$ ) as well as the activities of glutamate dehydrogenase (GLDH; $30.5 \mathrm{U} / \mathrm{L}$; normal 4 to $18 \mathrm{U} / \mathrm{L}$ ) and sorbitol dehydrogenase (SDH; $67.8 \mathrm{U} / \mathrm{L}$; normal 4 to $7 \mathrm{U} / \mathrm{L}$ ) were increased. An ELISA for bovine leukaemia virus (CHEKIT® BLV-ELISA kit, IDEXX Switzerland) was negative.

The bull was euthanised because of a grave prognosis and necropsied. At necropsy, numerous bulging or polypoid masses with a diameter of about $4.5 \times 3.5 \times 2 \mathrm{~cm}$ were observed in the left atrium (Fig. 1). Neoplastic mass was white-to-yellow, infiltrated the left atrium but did not extend into the myocardium. The mass was granular and bulged from the cut surfaces. No evidence of neoplasm beyond the ventricle was found and no other gross abnormalities were also observed.

The appropriate tissues from the mass were fixed in $10 \%$ neutral buffered formalin, dehydrated in graded ethanol, cleared in xylene, and embedded in paraffin wax. Sections of $5 \mu \mathrm{m}$ were stained with haematoxylin and eosin (H\&E) and studied microscopically.

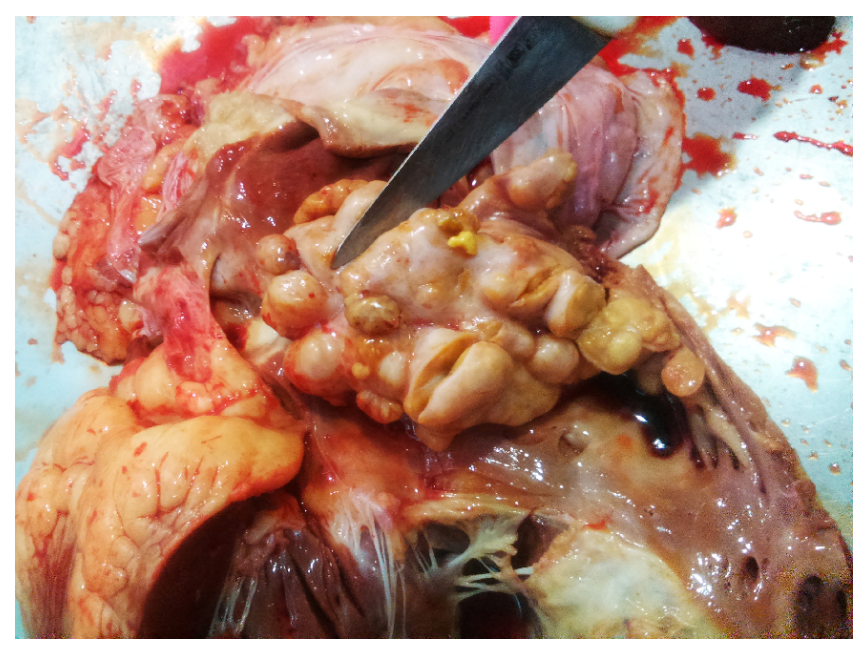

Fig. 1. Heart. Note numerous bulging or polypoid masses in the atrium. 


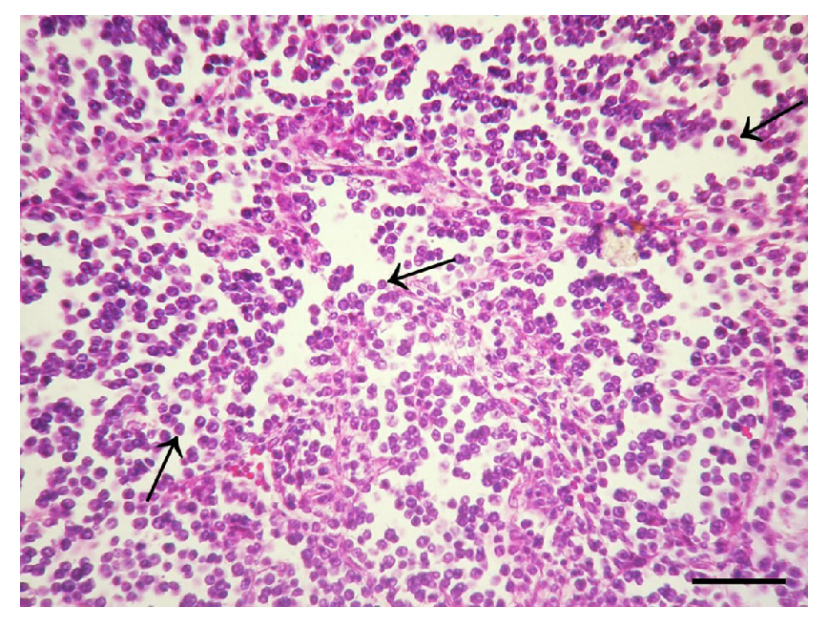

Fig. 2. Medium to large sized lymphocytic cells containing a round to oval nuclei with one nucleolus and stippled chromatin surrounded by a thin rim of pale eosinophilic cytoplasm (arrows) (H\&E, Bar $=30 \mu \mathrm{m})$.

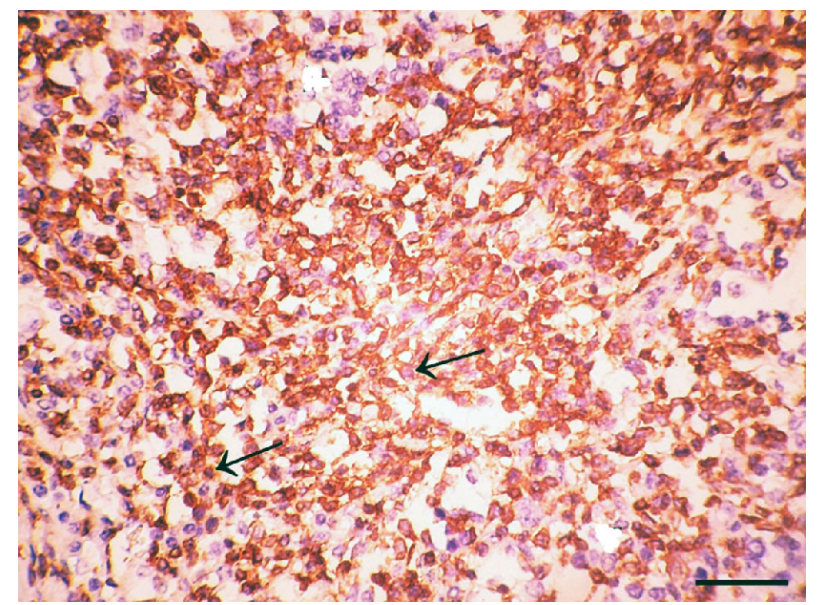

Fig. 3. The neoplastic cells show strong, diffuse, membranous expression of CD3 (arrows), indicating a T-cell lymphoma (IHC, Bar $=25 \mu \mathrm{m}$ ).

Immunohistochemical (IHC) analysis of the tumour sections was performed using monoclonal antibodies CD3 (Monoclonal Mouse Anti-Human CD3, Dako Cytomation), CD79a (Monoclonal Mouse Anti-Human CD79acy Clone HM57, Dako Cytomation), CD20 (monoclonal mouse anti-human CD20cy, Dako Cytomation), Ki67 (Monoclonal Mouse
Anti-Human Antigen Clone MIB-1, Dako Cytomation), S100 (polyclonal, 1:100; Dako Cytomation), vimentin (monoclonal mouse antibody clone V9, Dako Cytomation), and cytokeratin (Biogenex, AE1/ AE3, USA.).

Histopathological examination revealed the extensive infiltration of medium to large-sized lymphocytic cells. The 


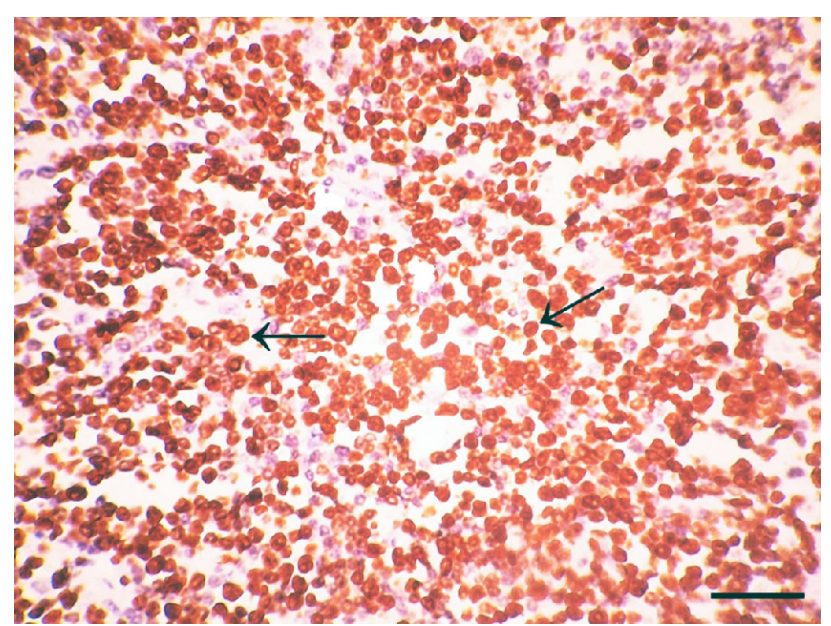

Fig. 4. The majority of neoplastic cells express the proliferation marker Ki-67 (arrows) (IHC, Bar=25 $\mu \mathrm{m}$ ).

neoplastic cells predominantly had round to oval nuclei with stippled chromatin as well as a nucleolus, surrounded by a narrow rim of pale eosinophilic cytoplasm (Fig. 2). There were moderate numbers of mitotic figures, some of which were atypical. The tumour cells were surrounded by a sparse fibrovascular stroma. No invasion into the myocardium was identified in tissue sections.

Immunohistochemical staining was positive for CD3 in neoplastic cells (Fig. 3 ). The proliferation marker Ki-67 was immunohistochemically expressed by the majority of neoplastic cells (95\%), reflecting a high proliferative rate (Fig. 4). Neoplastic cells were not stained with all other immunostains, including CD $79 \alpha$, CD20, $\mathrm{S} 100$, cytokeratin and vimentin.

Bovine lymphoma associated with bovine leukaemia virus infection usually occurs in adult cattle 4 to 8 years of age. The tumours have a predilection for the abomasum, uterus, right heart, and peripheral lymph nodes (Thurmond, 1996; Johnson, 1999; Welker, 1999). Based on epidemiological and clinicotopographical criteria, this neoplasm in cattle is classi- fied into enzootic bovine leukosis and sporadic bovine leukosis. EBL is endemic across the USA and occurs as multicentric lymphadenopathy in older cows; whereas the SBL is the predominant type of leukosis in Europe (Grünberg \& Eisenberg, 2013). The age of the affected also plays a critical role in presenting a classification: viral enzootic bovine leukosis occurs in adult cattle and SBL is detected in young cattle (Jacobs et al., 2002; Radostits et al., 2007; Grünberg \& Eisenberg, 2013). In the present report, T-cell lymphoma was detected in the atrium of a 1.5-year-old Holstein bull. Lymphomas are also subdivided into three further groups in calves: a) spontaneous tumours of the congenital type, occurring in foetuses, newborns and relatively young calves, b) spontaneous tumours of the juvenile type, occurring in older calves (aged 2-12 months), and c) iatrogenic tumours, such as skin papillomas caused by the papilloma virus after tattooing or dehorning (Misdorp, 2002).

The most obvious clinical symptom of lymphoma is the enlargement of peripheral lymph nodes (Johnson, 1999). Superficial lymph node enlargement occurs in 
$75-90 \%$ of cases (Malatestinic, 2003). A strange finding in this regard was the absence of this lesion in peripheral lymph nodes.

Histopathologically, the neoplasm was characterised by extensive infiltration of medium to large-sized lymphocytic cells being consistent with those reported by other researchers (Tani et al., 1997; Braun et al., 2015). The neoplastic cells predominantly had round to oval nuclei with stippled chromatin and one nucleolus surrounded by a narrow rim of pale eosinophilic cytoplasm. Similar histological features have frequently been reported for bovine lymphomas in previous studies (Step et al., 2001; Harbo et al., 2004). These histological features are compatible with those of large T-cell lymphoma, as previously reported in calves (Tani et al., 1997; Harbo et al., 2004; Braun et al., 2015).

CD3 and CD79 antibodies have been documented as effective reagents for the immunohistochemical assessment of T-/Bcell lineage lymphomas in animals, as in humans. CD3 (T-cell lymphocytes marker) and CD79a (B-cell lymphocytes marker) immunohistochemistry were used to classify the tumour as lymphoma. One type of lymphoma caused by bovine leukaemia virus is B-cell lymphoma (Jacobs et al., 2002), whereas sporadic bovine leukosis is more likely to be linked with $\mathrm{T}$ cells (Step et al., 2001; Jacobs et al., 2002). In this case, immunnostaining for CD3 was observed while immunolabelling of tumour cells for the CD79 antibody was not detected. Positivity with CD3 and negativity with CD20 and CD 79a indicated that tumour cells might originate from the immature T-lymphocytes, as documented in earlier studies (Kebriaei et al., 2003).
The proportion of proliferating cells can also be estimated by immunohistochemical assay of Ki-67 antigen expression, which has proven to be of effect in human oncology (Fournel-Fleury et al., 1997). Ki-67 is a highly conserved nonhistone nuclear antigen protein involved in maintaining chromosomal stability during mitosis (Phillips et al., 2000). In dogs with highly malignant T-cell lymphoma, Ki-67 index ranged from $50 \%$ to $70 \%$ (Fournel-Fleury et al., 1997). Ki-67 index was $95 \%$ in the present case, which was in agreement with the high mitotic index.

\section{ACKNOWLEDGEMENTS}

The authors are grateful to Mr. A. Pirzadeh from the Department of Pathobiology of the Faculty of Veterinary Medicine, Lorestan University, Khorramabad, Iran for his technical assistance.

\section{REFERENCES}

Braun, U., C. Brammertz, E. Maischberger, D. A. Bass, S. Klausmann \& T. Sydler, 2015. T-cell lymphoma in the nasal cavity of a Brown Swiss heifer. Acta Veterinaria Scandinavica, 57, 1-5.

Constantino, A., T. E. West, M. Gupta \& F. Loghmanee, 1987. Primary cardiac lymphoma in a patient with acquired immune deficiency syndrome. Cancer, 60, 28012805.

Fournel-Fleury, C., J. P. Magnol, L. Chabanne, I. Ghernati, T. Marchal, C. Bonnefond, P. A. Bryon \& P. Felman, 1997. Growth fractions in canine non-Hodgkin's lymphomas as determined in situ by the expression of the Ki-67 antigen. Journal of Comparative Pathology, 117, 61-72.

Grünberg, W. \& S. W. Eisenberg, 2013. Atypical form of sporadic bovine leukosis (SBL) in the Netherlands. The Veterinary Record, 173, 398. 
Harbo, S. J., G. M. Barrington, A. J. Allen, G. L. Sample, S. M. Parish, M. J. Hamilton \& W. C. Davis, 2004. Characterization of lymphocyte populations by flow cytometry in a calf with sporadic juvenile lymphoma. Veterinary Clinical Pathology, 33, 163167.

Holladay, A. O., R. J. Siegel \& D. A. Schwartz, 1992. Cardiac malignant lymphoma in acquired immune deficiency syndrome. Cancer, 70, 2203-2207.

Jacobs, R. M., J. B. Messick \& V. E. Valli, 2002. Tumors of the hemolymphatic system. In: Tumors in Domestic Animals, ed D. J. Meuten, Iowa: Iowa State Press.

Johnson, R., 1999. Bovine leukemia virus. In: Current Veterinary Therapy: Food Animal Practice, $4^{\text {th }}$ ed., ed. J. L. Howard \& R. A. Smith, WB Saunders, Philadelphia, PA, pp. 296-298.

Kebriaei, P., J. Anastasi \& R. A. Larson, 2003. Acute lymphoblastic leukaemia: Diagnosis and classification. Best Practice \& Research Clinical Haematology, 15, 597621.

Malatestinic, A., 2003. Bilateral exophthalmos in a Holstein cow with lymphosarcoma. Canadian Veterinary Journal, 44, 664666.

Meuten, D. J. \& J. W. Harvey, 2008. Tumors of the lymphoid and hematopoietic tissues. In: Tumors in Domestic Animals, $4^{\text {th }}$ edn, University of California Press, Berkeley, CA, pp. 231-307.

Misdorp, W., 2002. Tumors in calves: Comparative aspects. Journal of Comparative Pathology, 127, 96-105.

Phillips, B. S., P. H. Kass, D. K. Naydan, M. D. Winthrop, S. M. Griffey \& B. R. Madewell, 2000. Apoptotic and proliferation indexes in canine lymphoma. Journal of Veterinary Diagnostic Investigation, 12, 111-117.

Radostits, O. M., C. C. Gay, K. W. Hinchcliff \& P. D. Constable, 2007. Sporadic bovine leukosis. In: Veterinary Medicine. A Textbook of the Diseases of Cattle, Horses,
Sheep, Pigs, and Goats. Saunders Elsevier, Philadelphia, p. 1216-1277.

Sasaki, Y., N. Ishiguro, M. Horiuchi, M. Shinagawa, S. H. Furuoka, T. Matsui, M. Asahina \& K. Okada, 1997. Characterization of differentiation antigens expressed in bovine lymphosarcomas. Journal of Comparative Pathology, 116, 13-20.

Step, D. L., C. A. Cummings, R. N. Streeter, J. G. Kirkpatrick \& G. A. Campbell, 2001. An atypical lymphoma of T-cell lineage in the thorax of an aged cow. Journal of Veterinary Diagnostic Investigation, 13, 154158.

Tani, K., M. Asahina, D. L. Wu, T. Ajito, K. Murakami, M. Goryo, Y. Aida, C. William, W. C. Davis \& K. Okada, 1997. Further analysis of the phenotype and distribution of tumor cells in sporadic B-cell and T-cell lymphomas in the lymph node and spleen of cattle. Veterinary Immunology and Immunopathology, 55, 283-290.

Thurmond, M., 1996. Bovine lymphosarcoma. In: Large Animal Internal Medicine, ed. B. P. Smith, $2^{\text {nd }}$ edn, Mosby-Year Book, St. Louis, MO. pp. 1237-1242.

Welker, B., 1999. Adult lymphosarcoma. In: Current Veterinary Therapy: Food Animal Practice, $4^{\text {th }}$ edn, ed. J. L. Howard \& R. A. Smith, W. B. Saunders, Philadelphia, PA, p. 480.

Paper received 28.10.2016; accepted for publication 06.02.2017

\section{Correspondence:}

Ghasem Farjanikish, DVM, PhD

Department of Pathobiology,

Faculty of Veterinary Medicine, Lorestan University, Khorramabad, Iran e-mail: farjanikish.gh@lu.ac.ir 